\title{
A suplementação diária de guaraná em pó (Paullina cupana) em baixa dosagem influencia marcadores bioquímicos associados à aterosclerose.
}

\author{
SEEHABER, Andressa Duarte ${ }^{1}$; BARBISAN, Fernanda ${ }^{2}$; \\ SULEIMAN, Leila Atiyeh M. ${ }^{3}$; CRUZ, Ivana Beatrice M. ${ }^{4}$
}

\section{Resumo}

Introdução: O Guaraná (Paullina cupana), fruto típico do Amazonas consumido pelas populações tradicionais, já demonstrou atividade antioxidante, antiplaquetária, antiobesogênica, hipolipemiante e moduladora dos níveis de óxido nítrico (NO) em estudos prévios. Evidências sugerem que o consumo desse composto pode alterar o estabelecimento da aterosclerose, dessa forma propõe-se analisar se a suplementação diária em baixa dosagem e curto espaço de tempo de guaraná em pó influencia os marcadores sanguíneos associados a essa patologia, determinante nas doenças cardiovasculares. Método: Ensaio clínico randomizado, controlado por placebo, foi conduzido através da suplementação mínima diária de $90 \mathrm{mg}$ de guaraná em cápsulas, ingeridas por 14 dias por voluntários saudáveis com sobrepeso $(n=14)$. . Resultados: A suplementação com guaraná reduziu em $20 \%$ os níveis de triglicerídeos. Também houve diminuição nos níveis de ácido úrico, colesterol LDL e total, glicemia e albumina modificada por isquemia. Esses achados foram independentes de sexo e idade. Conclusões: Sugere-se que a dose mínima diária de guaraná apresentada no presente estudo tem efeito modulador

\footnotetext{
${ }^{1}$ Graduanda em Medicina pela Universidade Federal de Santa Maria (UFSM) e Iniciação Científica no Laboratório de Biogenômica-Centro de Ciências da Saúde-UFSM. Email: andressa_ds142@hotmail.com

${ }^{2}$ Doutoranda do Programa de Pós-Graduação em Farmacologia da UFSM. Email: fernandabarbisan@gmail.com

${ }^{3}$ Colaboradora Laboratório Biogenômica, Universidade Federal de Santa Maria -UFSM. Email: leila@farmabiz.com.br

${ }^{4}$ Professora e Orientadora dos Programas de Pós Graduação em Bioquímica Toxicológica e Farmacologia da Universidade Federal de Santa Maria. Email:ibmcruz@hotmail.com Agradecimentos: CNPq e CAPES
} 
positivo em certos biomarcadores de risco cardiovascular humano e ateroscleróticos, independentemente da perda de peso.

Palavras Chave: Paullina cupana; Marcadores bioquímicos; Doenças cardiovasculares 